\title{
Lack of an association human dioxin detoxification gene polymorphisms with endometriosis in Japanese women: results of a pilot study
}

\author{
Yasunari Matsuzaka $\cdot$ Yukie Y. Kikuti $\cdot$ Kenichi Goya • \\ Takahiro Suzuki $\cdot$ Li-yi Cai · Akira Oka $\cdot$ Hidetoshi Inoko • \\ Jerzy K. Kulski · Shun-ichiro Izumi · Minoru Kimura
}

Received: 15 December 2011 / Accepted: 28 March 2012/Published online: 1 May 2012

(c) The Japanese Society for Hygiene 2012

\begin{abstract}
Objectives Endometriosis is a chronic disease caused by the presence of endometrial tissue in ectopic locations outside the uterus. Chronic exposure to the environmental pollutant dioxin has been correlated with an increased incidence in the development of endometriosis in non-human primates. We have therefore examined whether there is an association between the polymorphisms of ten dioxin detoxification genes and endometriosis in Japanese women.
\end{abstract}

Electronic supplementary material The online version of this article (doi:10.1007/s12199-012-0281-y) contains supplementary material, which is available to authorized users.

Y. Matsuzaka ( $₫)$. Y. Y. Kikuti · A. Oka · H. Inoko ·

J. K. Kulski · M. Kimura ( $ه)$

Division of Basic Molecular Science and Molecular Medicine,

School of Medicine, Tokai University, Bohseidai, Isehara,

Kanagawa 259-1193, Japan

e-mail: yasunari.matsuzaka@helmholtz-muenchen.de

M. Kimura

e-mail: kimura@is.icc.u-tokai.ac.jp

Present Address:

Y. Matsuzaka

Institute of Experimental Genetics, Helmholtz Zentrum

München, German Research Center for Environmental Health,

Neuherberg, Germany

K. Goya · T. Suzuki · L. Cai · S. Izumi $(\bowtie)$

Department of Obstetrics and Gynecology, School of Medicine,

Tokai University, Bohseidai, Isehara, Kanagawa 259-1193,

Japan

e-mail: s-izumi@is.icc.u-tokai.ac.jp

J. K. Kulski

Centre for Forensic Science, The University of Western

Australia, Nedlands, WA 6009, Australia
Methods This was a pilot study in which 100 patients with endometriosis and 143 controls were enrolled. The prevalence of five microsatellite and 28 single nucleotide polymorphism markers within ten dioxin detoxification genes (AhR, AHRR, ARNT, CYPIA1, CYP2E1, EPHX1, GSTM1, GSTP1, GSTT1, NAT2) was examined.

Results Taking into account that this analysis was a preliminary study due to its small sample size and genetic power, the results did not show any statistically significant difference between the cases and controls for any of the allele and genotype frequency distributions examined. In addition, no significant associations between the allele/ genotype of all polymorphisms and the stage (I-II or IIIIV) of endometriosis were observed.

Conclusion Based on the findings of this pilot study, we conclude the polymorphisms of the ten dioxin detoxification genes analyzed did not contribute to the etiology of endometriosis among our patients.

Keywords Endometriosis - Dioxin detoxification genes · Single nucleotide polymorphisms $\cdot$ Microsatellite .

Association study

\section{Introduction}

Endometriosis (MIM131200) is an estrogen-dependent inflammatory disease that is characterized histologically by the presence of endometrial glands and stroma outside the uterine cavity. Approximately $6-10 \%$ of women of reproductive age have been reported to suffer from this condition $[1,2]$. In a study of the genetic influence on the risk of endometriosis among twins in Australia, the risk ratio of affected versus population prevalence was 3.58 for monozygotic twins and 2.32 for dizygotic twins [3]. A strong familial occurrence, 
in which the incidence of the disease is approximately sevenfold higher in relatives of women with endometriosis than in those without family history, supports a genetic role [4, 5].

Ligand-bound $A h R$ translocates to the nucleus, where it heterodimerizes with $A R N T$. The $A h R-A R N T$ heterodimer binds to xenobiotic response element sequences and induces the activation of the target genes that encode the cytochrome P450 enzymes CYP1A1 and CYP2E1 [6]. In this heterodimer formation, the $A h R R$ competes with $A h R$ to repress the expression of $A h R$ regulatory genes [7]. Crosstalk between dioxin-activated $A h R$ and the functional estrogen receptor (ER) has been reported [8]. Dioxin has also been shown to induce a dose-dependent increase in the severity of endometriosis in rhesus monkeys [9].

In order to gain a better understanding of the association between detoxification genes and endometriosis in Japanese women, we performed a case-control study of endometriosis as pilot study involving 100 cases and 143 controls.

\section{Methods}

\section{Subjects}

All patients and controls were female and had given their written informed consent (IC), following an explanation of the laparoscopy and histological examination, to participate in this study, which was performed at the Department of Obstetrics and Gynecology, Tokai University School of Medicine. The rate of approval was almost $100 \%$ after a reflection period between the explanation and admittance to the hospital. The patients with endometriosis were diagnosed by laparoscopy and histological examination, and the severity of disease was staged according to the revised classification of the American Society of Reproductive Medicine (r-ASRM) [10]. Of the 100 endometriosis cases (mean age of patient $38 \pm 4.8$ years), 27, 10, 31, 32 cases were classified as stage I, II, III, and IV levels of disease, respectively. The 143 healthy controls (mean age $43 \pm 12.3$ years) were patients of unexplained infertility who had undergone a diagnostic laparoscopy that proved the absence of endometriosis (Table 1). Patients with apparent disease(s) were excluded from the control group. Ethics approval for this study was obtained from the Institutional Review Board at Tokai University School of Medicine.

\section{DNA extraction}

Genomic DNA samples were isolated from peripheral blood leukocytes that were drawn from each subject into tubes containing heparin by using the Qiagen DNA Extraction kit (Qiagen, Tokyo, Japan) after lysis with proteinase $\mathrm{K}$ and $0.5 \%$ sodium dodecyl sulfate at $37{ }^{\circ} \mathrm{C}$ for $1 \mathrm{~h}$.
Table 1 Characteristics of cases of endometriosis and controls

\begin{tabular}{|c|c|c|}
\hline Study cohort & Cases & Controls \\
\hline Number of patients & 100 & 143 \\
\hline Age (years) ${ }^{\mathrm{a}}$ & $38 \pm 4.8$ & $43 \pm 12.3$ \\
\hline \multicolumn{3}{|l|}{ Endometriosis stage $^{\mathrm{b}}$} \\
\hline Stage I & $27(27.0)$ & \\
\hline Stage II & $10(10.0)$ & \\
\hline Stage III & $31(31.0)$ & \\
\hline Stage IV & $32(32.0)$ & \\
\hline Smoking $(\%)^{\mathrm{c}}$ & 14.7 & 14.7 \\
\hline Body mass index ${ }^{\mathrm{d}}$ & $20.6 \pm 3$ & $21.5 \pm 3$ \\
\hline \multicolumn{3}{|c|}{$\begin{array}{l}\text { b Number of patients, with the percentage (of } 100 \text { cases) given in } \\
\text { parenthesis }\end{array}$} \\
\hline \multicolumn{3}{|c|}{ d Mean and standard deviation for 32 cases and 30 controls } \\
\hline
\end{tabular}

Analysis of microsatellite polymorphisms in the $A h R$ and $A R N T$ gene regions

To determine the number of repeat units of the microsatellite loci exhibiting polymorphisms in the $A h R$ and $A R N T$ genes, we synthesized unilateral primers by labeling the $5^{\prime}$ end with the fluorescent reagent 6-FAM (PE Biosystems, Foster City, CA). Two and four PCR primer sets were used for the amplification of two and four microsatellite loci in $A h R$ and ARNT gene regions, respectively [Electronic Supplementary Material (ESM) Table 1]. PCR amplification and GenScan (Applied Biosystems Japan, Tokyo, Japan) detection of these microsatellites were carried out as previously described [11].

\section{Genotyping}

To examine the distribution of the alleles and genotype frequency of each single nucleotide polymorphism (SNP) and deletion, we performed direct sequencing analysis of ten endometriosis candidate genes using 25 pairs of oligonucleotide PCR primers (ESM Table 2). The reaction mixture $(20 \mu \mathrm{l})$ contained $2 \mathrm{ml}$ of dNTP mixture $(2.5 \mathrm{mM}$ each of dATP, dCTP, dGTP, and dTTP), genomic DNA $(5 \mathrm{ml} ; 2 \mathrm{ng} / \mu \mathrm{l}), 2 \mathrm{ml}$ of $10 \times$ buffer $(100 \mathrm{mM}$ Tris $-\mathrm{HCl}$, $\mathrm{pH} 8.3,500 \mathrm{mM} \mathrm{KCl}, 15 \mathrm{mM} \mathrm{MgCl} 2), 20$ pmol of forward and reverse primers, and $0.5 \mathrm{U}$ of rTaq (TaKaRa Bio, Shiga, Japan). PCR amplification was performed in a GeneAmp PCR system 9700 automated thermal cycler (Applied Biosystems Japan) under the following PCR reaction conditions: an initial denaturation for $5 \mathrm{~min}$ at $96{ }^{\circ} \mathrm{C}$, followed by 30 amplification cycles of $45 \mathrm{~s}$ at $96{ }^{\circ} \mathrm{C}, 45 \mathrm{~s}$ at various temperatures depending on the 
primers used (ESM Table 2) for annealing, and $2 \mathrm{~min}$ at $72{ }^{\circ} \mathrm{C}$, with a final extension of $7 \mathrm{~min}$ at $72^{\circ} \mathrm{C}$. Each PCR product was purified by exonuclease $\mathrm{I}$ and then sequenced using an ABI 3100 automated sequencer (Applied Biosystems Japan).

\section{Statistical analyses}

Allele and genotype frequencies were determined by direct counting. The significance of differences in the distribution of alleles and genotypes between the patients and controls was tested using a case-control design by the Fisher's exact probability test $\left(P\right.$ value test). A $P_{\mathrm{c}}$ of $<0.05$, which indicates significant corrections for multiple testing, such as the Bonferroni method $[P \times L \times(n-1)]$, was considered to indicate statistical significance for all allelic and genotypic frequencies where $P, L$, and $n$ indicate the $P$ value, number of loci examined, and the number of alleles examined, respectively. The odds ratio (OR) and $95 \%$ confidence interval (CI) were also calculated for all SNPs. The program Haploview (MIT/Harvard Broad Institute, Cambridge, MA) was used to estimate pairwise linkage disequilibrium (LD) and haplotype frequency [12]. The Genetic Power Calculator was used to calculate a genetic power for association study (http://pngu.mgh. harvard.edu/ purcell/gpc/).

\section{Results}

Association of microsatellite markers around the $A h R$ and $A R N T$ genes with endometriosis

A total of 100 Japanese patients with endometriosis and 143 healthy controls were enrolled in our analysis aimed at investigating the association between genetic variations in the $A h R$ and ARNT genes and endometriosis. To this end, we used six microsatellites found in close proximity and within the region of the $A h R$ and $A R N T$ genes (Table 2). The two microsatellites with the dinucleotide repeat
(AC) $n$ and (CA)n were positioned 1,206 and $882 \mathrm{bp}$ upstream of the exons 2 and 3 in the $A h R$ gene region, respectively. The other four microsatellites, with di- to pentanucleotide repeats (TG)n, (TAA), (ATTT)n, and (TTTTG)n, were positioned 9,907 and 10,880 bp upstream of the first methionine of exon, 16,306 bp upstream of exon 2 , and 2,642 bp upstream of exon 14, respectively, in the ARNT gene. As shown in Table 2, the microsatellite with the CA repeats, at intron 2 of the $A h R$ gene and the four microsatellites in the $A R N T$ gene region had no statistically significant association with endometriosis. The other microsatellite with the dinucleotide repeat (AC) $n$ in the $A h R$ gene region was not polymorphic (data not shown).

Association of endometriosis candidate gene polymorphisms with endometriosis

Twenty-eight SNPs in the $A h R, A H R R, A R N T, C Y P 1 A 1$, CYP2E1, EPHX1, GSTP1, and NAT2 genes were genotyped in all 100 patients with endometriosis and 143 controls. The allele frequencies of each polymorphism are shown in Table 3. There was no significant association found between the gene polymorphisms and the presence of endometriosis. However, the TT genotypes in intron 10 (rs2106728) of the AhR gene showed a prominent-but not significant-association with the risk of developing endometriosis (Table $4, P_{\mathrm{c}}=0.087$ ). To also test whether there was an association between endometriosis and the glutathione S-transferase (GST) M1 and T1 null mutation, we genotyped these genotype frequencies in 97 patients with endometriosis and 143 controls. No significant differences were found between the cases and controls for the frequencies of the GSTM1 and GSTT1 null mutations (Table 4).

We evaluated the LD extension of approximately $42 \mathrm{~kb}$ of the $A h R$ genomic region with 12 SNPs. For the LD block evaluation, we included SNPs with a minor allele frequency of $>0.2$, a genotype success rate of $>0.8$, and $P>0.001$ in the Hardy-Weinberg equilibrium test. All SNPs analyzed met the criteria, and the pairwise LD index

Table 2 Results of the association tests for five microsatellite markers with endometriosis

\begin{tabular}{llrlccccc}
\hline Gene & Location & Position $^{\mathrm{a}}$ & Repeat unit & Number of alleles & Patients $^{\mathrm{b}}$ & Controls $^{\mathrm{b}}$ & Odds ratio $(90 \% \text { CI })^{P}$ value \\
\hline$A h R$ & Intron 2 & 22,322 & (CA) $n$ & 8 & $39(24.1)$ & $49(20.9)$ & $1.20(0.74-1.93)$ & 0.461 \\
$A R N T$ & Promoter & $-10,880$ & (TAA) $n$ & 3 & $65(50.8)$ & $79(44.9)$ & $1.27(0.80-2.00)$ & 0.309 \\
$A R N T$ & Promoter & $-9,907$ & (TG) $n$ & 14 & $20(17.2)$ & $20(12.2)$ & $1.50(0.77-2.93)$ & 0.235 \\
$A R N T$ & Intron 1 & 11,774 & (ATTT) $n$ & 2 & $20(17.5)$ & $21(15.4)$ & $1.17(0.60-2.28)$ & 0.655 \\
$A R N T$ & Intron 13 & 55,880 & (TTTTG) $n$ & 3 & $107(75.9)$ & $128(68.8)$ & $1.43(0.87-2.34)$ & 0.159 \\
\hline
\end{tabular}

CI, Confidence interval

${ }^{\text {a }}$ Position is the number of nucleotides from the first nucleotide (A) of the start codon

b Data are presented as the number with the percentage in parenthesis 
Table 3 Nucleotide variations within the human candidate genes and the significance of their association with endometriosis

\begin{tabular}{|c|c|c|c|c|c|c|c|c|c|}
\hline \multirow[t]{2}{*}{ Gene } & \multirow{2}{*}{$\begin{array}{l}\text { dbSNP } \\
\text { accession no. }\end{array}$} & \multirow[t]{2}{*}{ Location } & \multirow[t]{2}{*}{ Allele $^{\mathrm{a}}$} & \multirow{2}{*}{$\begin{array}{l}\text { Amino acid } \\
\text { substitution }\end{array}$} & \multicolumn{2}{|c|}{ Allele frequency ${ }^{\mathrm{b}}$} & \multirow[t]{2}{*}{ OR $(90 \% \mathrm{CI})$} & \multirow[t]{2}{*}{$P$ value } & \multirow[t]{2}{*}{$P_{\mathrm{c}}$ value } \\
\hline & & & & & Patients & Controls & & & \\
\hline \multirow[t]{12}{*}{$A h R$} & rs713150 & Intron 1 & $\mathrm{C} / \mathrm{g}$ & - & $79(40.7)$ & $87(30.4)$ & $1.57(1.07-2.30)$ & 0.020 & 0.540 \\
\hline & rs2282886 & Intron 1 & $\mathrm{~A} / \mathrm{g}$ & - & $109(69.9)$ & $157(66.5)$ & $1.17(0.75-1.80)$ & 0.487 & 1.000 \\
\hline & rs2237299 & Intron 1 & $\mathrm{~T} / \mathrm{c}$ & - & $139(73.2)$ & $192(68.1)$ & $1.28(0.85-1.92)$ & 0.238 & 1.000 \\
\hline & rs2237298 & Intron 1 & $\mathrm{~T} / \mathrm{c}$ & - & $139(73.2)$ & $192(68.1)$ & $1.28(0.85-1.92)$ & 0.238 & 1.000 \\
\hline & rs3802083 & Intron 1 & $\mathrm{~T} / \mathrm{c}$ & - & $131(68.2)$ & $186(65.5)$ & $1.13(0.77-1.67)$ & 0.535 & 1.000 \\
\hline & rs2282883 & Intron 2 & $\mathrm{~T} / \mathrm{c}$ & - & $122(69.3)$ & $170(65.9)$ & $1.17(0.78-1.76)$ & 0.455 & 1.000 \\
\hline & rs 1476080 & Intron 2 & $\mathrm{~T} / \mathrm{g}$ & - & $131(68.2)$ & $183(66.3)$ & $1.09(0.74-1.62)$ & 0.663 & 1.000 \\
\hline & rs2237297 & Intron 2 & G/a & - & $86(45.7)$ & $127(45.4)$ & $1.02(0.70-1.02)$ & 0.934 & 1.000 \\
\hline & rs3802082 & Intron 5 & $\mathrm{~A} / \mathrm{t}$ & - & $100(52.6)$ & $131(52.0)$ & $1.03(0.70-1.50)$ & 0.893 & 1.000 \\
\hline & rs2066853 & Exon 10 & G/a & Arg/Lys & $91(47.9)$ & $155(45.8)$ & $1.09(0.75-1.57)$ & 0.654 & 1.000 \\
\hline & rs2040623 & Intron 10 & $\mathrm{C} / \mathrm{a}$ & - & $96(49.5)$ & $137(47.9)$ & $1.07(0.74-1.53)$ & 0.734 & 1.000 \\
\hline & rs2106728 & Intron 10 & $\mathrm{~T} / \mathrm{c}$ & - & $169(87.1)$ & $219(76.6)$ & $2.07(1.26-3.39)$ & 0.004 & 0.108 \\
\hline$A H R R$ & rs2292596 & Exon 6 & $\mathrm{C} / \mathrm{g}$ & Pro/Ala & $69(37.5)$ & $103(36.8)$ & $1.03(0.70-1.51)$ & 0.876 & 1.000 \\
\hline \multirow[t]{3}{*}{$A R N T$} & rs11204735 & Intron 1 & $\mathrm{~A} / \mathrm{g}$ & - & $84(46.7)$ & $112(43.8)$ & $1.13(0.77-1.65)$ & 0.547 & 1.000 \\
\hline & rs3768015 & Intron 5 & $\mathrm{C} / \mathrm{t}$ & - & $127(66.8)$ & $164(61.2)$ & $1.28(0.87-1.89)$ & 0.216 & 1.000 \\
\hline & rs 10305711 & Intron 9 & $\mathrm{~A} / \mathrm{g}$ & - & 127 (67.6) & $177(62.8)$ & $1.24(0.84-1.82)$ & 0.287 & 1.000 \\
\hline \multirow[t]{6}{*}{$C Y P 1 A 1$} & rs3826042 & Promoter & $\mathrm{G} / \mathrm{a}$ & - & $157(89.2)$ & $220(84.6)$ & $1.50(0.84-2.68)$ & 0.169 & 1.000 \\
\hline & rs3826041 & Promoter & $\mathrm{T} / \mathrm{g}$ & - & $73(41.5)$ & $104(40.0)$ & $1.06(0.72-1.57)$ & 0.758 & 1.000 \\
\hline & rs4646421 & Intron 1 & $\mathrm{C} / \mathrm{t}$ & - & $71(37.0)$ & $90(31.9)$ & $1.25(0.85-1.84)$ & 0.253 & 1.000 \\
\hline & rs4646422 & Exon 2 & $\mathrm{G} / \mathrm{a}$ & Gly/Asp & $29(14.9)$ & $32(11.3)$ & $1.37(0.80-2.35)$ & 0.248 & 1.000 \\
\hline & rs1048943 & Exon 7 & $\mathrm{~A} / \mathrm{g}$ & Ile/Val & $46(24.2)$ & $61(22.3)$ & $1.12(0.72-1.73)$ & 0.624 & 1.000 \\
\hline & rs5030838 & $3^{\prime}$ flanking region & $\mathrm{T} / \mathrm{c}$ & - & $72(37.1)$ & $92(32.4)$ & $1.23(0.84-1.81)$ & 0.286 & 1.000 \\
\hline$C Y P 2 E 1$ & rs2070673 & Promoter & $\mathrm{T} / \mathrm{a}$ & - & $95(55.9)$ & $133(54.5)$ & $1.06(0.71-1.06)$ & 0.782 & 1.000 \\
\hline \multirow[t]{2}{*}{ EPHX1 } & rs1051740 & Exon 3 & $\mathrm{~T} / \mathrm{c}$ & Tyr/His & $113(58.2)$ & $145(51.1)$ & $1.34(0.93-1.93)$ & 0.121 & 1.000 \\
\hline & rs2292566 & Exon 3 & G/a & synonymous & $57(29.4)$ & $76(26.8)$ & $1.14(0.76-1.71)$ & 0.530 & 1.000 \\
\hline \multirow[t]{2}{*}{ GSTP1 } & rs 1695 & Exon 5 & $\mathrm{~A} / \mathrm{g}$ & Ile/Val & $29(14.9)$ & $40(14.1)$ & $1.07(0.64-1.80)$ & 0.792 & 1.000 \\
\hline & rs4891 & Exon 7 & $\mathrm{~T} / \mathrm{c}$ & synonymous & $165(85.1)$ & $239(84.2)$ & $1.07(0.65-1.78)$ & 0.790 & 1.000 \\
\hline NAT2 & rs1799930 & Exon 2 & G/a & Arg/Gln & $131(74.4)$ & $183(73.2)$ & $1.07(0.69-1.65)$ & 0.776 & 1.000 \\
\hline
\end{tabular}

dbSNP, Single Nucleotide Polymorphism Database; OR, odds ratio; CI, confidence interval

${ }^{a}$ In the allele column, a nucleotide on the left-hand side of the slash is a more frequent allele in the controls; each allele is represented by the nucleotide sequence of the sense strand of each gene

b Allele frequency is presented as the number, with the percentage in parenthesis; frequencies listed are higher in the patients than in the controls

Table 4 Genotype frequencies of the human AhR, GSTM1, and GSTT1 genes and the significance of their association with endometriosis

\begin{tabular}{|c|c|c|c|c|c|c|c|}
\hline \multirow[t]{2}{*}{ Gene } & \multirow[t]{2}{*}{ dbSNP accession no. } & \multirow[t]{2}{*}{ Genotype $^{\mathrm{a}}$} & \multicolumn{2}{|c|}{ Genotype frequency } & \multirow[t]{2}{*}{ OR $(90 \% \mathrm{CI})$} & \multirow[t]{2}{*}{$P$ value } & \multirow[t]{2}{*}{$P_{\mathrm{c}}$ value } \\
\hline & & & Patients $(\%)$ & Controls $(\%)$ & & & \\
\hline \multirow[t]{3}{*}{$A h R$} & rs2106728 & $\mathrm{CC}$ & $1(1.0)$ & $5(3.5)$ & & & \\
\hline & - & $\mathrm{CT}$ & $23(23.7)$ & $57(39.9)$ & & & \\
\hline & - & $\mathrm{TT}$ & $73(75.3)$ & $81(56.6)$ & $2.33(1.33-4.08)$ & 0.003 & 0.087 \\
\hline \multirow[t]{2}{*}{ GSTM1 } & - & Deletion & $43(44.3)$ & $67(46.9)$ & & & \\
\hline & - & Present & $54(55.7)$ & $76(53.1)$ & $1.11(0.66-1.86)$ & 0.700 & 1.000 \\
\hline \multirow[t]{2}{*}{ GSTT1 } & - & Deletion & $38(39.2)$ & $56(39.2)$ & & & \\
\hline & - & Present & $59(60.1)$ & $87(60.1)$ & $1.00(0.59-1.69)$ & 0.998 & 1.000 \\
\hline
\end{tabular}

${ }^{a}$ Each genotype is represented by the nucleotide sequence of the sense strand of each gene 
Table 5 Association between $A h R$ gene haplotypes and endometriosis

\begin{tabular}{|c|c|c|c|c|c|}
\hline Haplotype no. & Haplotype & Patients $(\%)$ & Controls $(\%)$ & $P$ value & $P_{\mathrm{c}}$ value \\
\hline Hap1 & TATACT & 0.409 & 0.348 & 0.169 & 0.506 \\
\hline Hap2 & TGAGAT & 0.217 & 0.139 & 0.024 & 0.072 \\
\hline Hap3 & GGAGAT & 0.151 & 0.121 & 0.926 & 1.000 \\
\hline
\end{tabular}

Haplotypes with a frequency of $<0.1$ were not included in the table. The $P_{\mathrm{c}}$ value was corrected for three tests

$(\Delta)$ was calculated and plotted (ESM Fig. 1). We further analyzed the haplotype constitution with six SNPs, namely, rs1476080, rs2237297, rs3802082, rs2066853, rs2040623, and rs2106728. Three haplotypes were estimated to have a frequency of $>0.1$ using Haploview. Haplotype 2 (TGAGAT) was more frequently observed in patients, but not significantly so, with a difference in frequency between the case and the control group of $P_{\mathrm{c}}=0.072$ (Table 5).

Although we evaluated whether all polymorphisms were also associated with any of the four stage of endometriosis, we found that all SNPs were not significantly associated with stages I/II and III/IV of endometriosis. However, the frequencies of the allele and the TT genotype in intron 10 (rs2106728) of the AhR gene showed a significant association with developing the severe stage (stage III/IV) of endometriosis without corrections for multiple testing (ESM Table 3a, $P=0.012$ and 0.008 , respectively). To assess the relationship between smoking and rs2106728, we examined the allele and genotype frequencies of five smoking patients and five smoking controls, or 29 nonsmoking patients and 29 non-smoking controls. Although no significant differences were found between the cases and controls in the smoking group, the frequencies of the allele and the TT genotype for rs2106728 showed a significant association in the non-smoking group without corrections for multiple testing (ESM Table 3b, $P=0.016$ and 0.017 , respectively).

\section{Discussion}

The aim of this pilot study, in which 100 cases and 143 controls were enrolled, was to evaluate whether the polymorphisms and null mutations in the dioxin receptor, the regulatory factor, and the phase I/II drug-metabolizing genes AhR, AHRR, ARNT, CYP1A1, CYP2E1, EPHXI, GSTM1, GSTP1, GSTT1, and NAT2 are associated with the susceptibility of endometriosis. Our results indicate a failure to detect a significant association between polymorphisms of dioxin detoxification genes and endometriosis in this small number of subjects. However, the TT genotypes in intron 10 (rs2106728) of the $A h R$ gene showed a prominent-but not significant-association with the risk of developing endometriosis (Table $4, P_{\mathrm{c}}=0.087$ ), leading us to calculate the genetic power in this association study (ESM Table 4). The genetic power for significance at $P=0.05$ is 0.505 and the number of cases required for $80 \%$ power is 192 ; moreover, the genetic power at $P=0.001$ is 0.096 and number of cases required for $80 \%$ power is 392 . However, if genetic power is increased simply by increasing the number of subjects, the effect sizes in the risk loci for complex diseases identified using the association study of genetic polymorphisms with a disease are typically small. The problem could be overcome using a classification by some risk factors, such as serum cytokines and growth factors and exposure of patients to dioxins, because some association of genetic polymorphisms of immunological factors, cytokines and growth factors with endometriosis has been reported, in addition to higher levels of dioxin in peritoneal fluid [13, 14]. In addition, there have been two recent genome-wide association studies which have demonstrated strong associations between $C D K N 2 B A S$ (antisense non-coding RNA in the cyclin-dependent kinase inhibitor 2A locus), Wnt4, and an intergenic region upstream of the NFE2L3 and HOXA1O genes and endometriosis $[15,16]$. The $C D K N 2 B A S$ and HOXA10 genes are involved in the regulation of cell growth and Wnt4 plays a role in the development of the female genital tract. Although the ethnic populations in these two studies comprised Japanese, Australia and UK populations, the association of Wnt4 with endometriosis in both studies was shown. This finding may suggest that the etiology of endometriosis is common between populations but that risk variants are often population-specific.

In conclusion, we have genotyped five microsatellites, 23 SNPs and two deletion markers in human dioxin detoxification genes using 100 Japanese patients with endometriosis and 143 controls as pilot study. However, there were no statistically significant differences in the genotype or allele frequency distributions between the cases and controls. Overall, these results suggest that these genetic variations analyzed in this study do not appear to contribute to the development of endometriosis. However, additional studies on different female populations are required to further confirm its role in the pathogenesis of endometriosis. 
Acknowledgments This study was partly supported by Health Sciences Research grants from the Ministry of Health, Labor and Welfare of Japan. We thank the members of Teaching and Research Support Center, Tokai University for DNA sequencing.

\section{Conflict of interest None.}

\section{References}

1. Bulun SE. Endometriosis. N Engl J Med. 2009;360:268-79.

2. Giudice LC, Kao LC. Endometriosis. Lancet. 2004;364(9447): 1789-99.

3. Treloar SA, O'Connor DT, O'Connor VM, Martin NG. Genetic influences on endometriosis in an Australian twin sample. Fertil Steril. 1999;71:701-10.

4. Simpson JL, Elias S, Malinak LR, Buttram VC Jr. Heritable aspects of endometriosis. I. Genetic studies. Am J Obstet Gynecol. 1980;137:327-31.

5. Matalliotakis IM, Arici A, Cakmak H, Goumenou AG, Koumantakis G, Mahutte NG. Familial aggregation of endometriosis in the Yale Series. Arch Gynecol Obstet. 2008;278(6): 507-11.

6. Swanson HI. DNA binding and protein interactions of the AHR/ ARNT heterodimer that facilitate gene activation. Chem Biol Interact. 2002;141:63-76.

7. Haarmann-Stemmann T, Abel J. The arylhydrocarbon receptor repressor (AhRR): structure, expression, and function. Biol Chem. 2006;387:1195-9.
8. Ohtake F, Takeyama K, Matsumoto T, Kitagawa H, Yamamoto Y, Nohara K, et al. Modulation of oestrogen receptor signalling by association with the activated dioxin receptor. Nature. 2003; 423:545-50.

9. Rier SE, Martin DC, Bowman RE, Dmowski WP, Becker JL. Endometriosis in rhesus monkeys (Macaca mulatta) following chronic exposure to 2,3,7,8-tetrachlorodibenzo- $p$-dioxin. Fundam Appl Toxicol. 1993;21:433-41.

10. Revised American Society for Reproductive Medicine classification of endometriosis: 1996. Fertil Steril. 1997;67:817-21.

11. Matsuzaka Y, Makino S, Okamoto K, Oka A, Tsujimura A, Matsumiya K, et al. Susceptibility locus for non-obstructive azoospermia is localized within the HLA-DR/DQ subregion: primary role of DQB $1 * 0604$. Tissue Antigens. 2002;60:53-63.

12. Barrett JC, Fry B, Maller J, Daly MJ. Haploview: analysis and visualization of $\mathrm{LD}$ and haplotype maps. Bioinformatics. 2005;21:263-5.

13. Zondervan KT, Cardon LR, Kennedy SH. The genetic basis of endometriosis. Curr Opin Obstet Gynecol. 2001;13:309-14.

14. Cai LY, Izumi S, Suzuki T, Goya K, Nakamura E, Sugiyama T, et al. Dioxins in ascites and serum of women with endometriosis: a pilot study. Hum Reprod. 2011;26:117-26.

15. Uno S, Zembutsu H, Hirasawa A, Takahashi A, Kubo M, Akahane T, et al. A genome-wide association study identifies genetic variants in the CDKN2BAS locus associated with endometriosis in Japanese. Nat Genet. 2010;42:707-10.

16. Painter JN, Anderson CA, Nyholt DR, Macgregor S, Lin J, Lee $\mathrm{SH}$, et al. Genome-wide association study identifies a locus at 7 p15.2 associated with endometriosis. Nat Genet. 2011;43:51-4. 